\title{
The Influence of Smallholders' Psychological Characteristics on Vietnam's Socio - Economic Development
}

\author{
Cao Thi Sinh \\ $\mathrm{PhD}$, Hanoi National University of Education, Viet Nam
}

\begin{abstract}
The Influence Of Smallholders' Psychological Characteristics On Vietnam's is a type of social psychology, including phenomena such as feelings, moods, beliefs, wishes, needs, habits, customs... of the farming class. People are formed under the direct influence of the smallholders' psychological economy; The unique working and living conditions of farmers, agriculture and rural areas have produced, decided and influenced their attitudes, behaviours, and behaviours. It has a positive (positive) negative (negative) impact on socio - economic development in Vietnam. The article focuses on analyzing and clarifying: "The influence of smallholders' psychological mentality on socio-economic development in Vietnam today", thereby proposing some basic solutions to promote the positive effects and overcome the negative effects of the smallholders' psychological for socio-economic development in Vietnam today.
\end{abstract}

Keywords: Smallholders' psychological, positive influence, negative influence, socio-economic, Vietnam.

DOI: $10.7176 /$ RHSS/11-14-07

Publication date:July $31^{\text {st }} 2021$

\section{Preamble}

The psychology of smallholders' psychological in Vietnam is a type of social psychology, including phenomena such as feelings, moods, beliefs, wishes, needs, habits, customs... of the farming class. people are formed under the direct influence of the smallholders' psychological economy; The unique working and living conditions of farmers, agriculture and rural areas have produced, decided and influenced their attitudes, behaviours, and behaviours.

The psychology of smallholders' psychological in Vietnam has the following characteristics: patriotism, community solidarity, love of labor, diligence, thrift, optimism in life; respecting people, respecting emotions, respecting morality, respecting honor, psychology of small-scale production, being conservative, inclined to experiential thinking; narrow-minded, selfish, local, liberal, arbitrary, less disciplined, disciplined, more than the law... These psychological characteristics exist boldly, present in the population classes in Vietnam. It affects both positively and negatively the socio-economic development in Vietnam today. Therefore, it is necessary to analyze and clarify the influence of smallholder mentality on economic development in Vietnam in both positive and negative aspects, thereby finding solutions to promote economic development. positive effects and overcoming the negative influence of smallholders' psychological mentality on socio-economic development is necessary and an important task in Vietnam today.

\section{Research Methods}

In order to clarify the concept of smallholders' psychological and its influence on socio-economic development in Vietnam today, we rely on the methodological basis of dialectical materialism and materialism. history, along with the use of basic research methods such as: analytical-synthetic method, logical-historical method, deductive-inductive method, comparative and contrasting method, etc. as inheriting data from published works of scientists.

\section{Research content}

\subsection{The concept of social psychology and smallholders' psychological in Vietnam}

\subsubsection{Psychosocial concept}

In the Dictionary of Philosophy, the concept of socio-psychology is understood as "the totality of feelings, wills, moods, habits... expressed in the psychology of social groups, classes, and ethnic groups", people of countries because of the common socio-economic conditions in their lives". ${ }^{1}$ According to the point of view of historical materialism, social existence determines social consciousness, but social consciousness is relatively independent, affecting social existence. Mark writes: "It is not man's consciousness that determines his existence; On the contrary, their existence determines their consciousness" ${ }^{2}$. In social consciousness, ideology and social psychology are the two main parts constituting its content. Thus, social psychology is a part of social consciousness, determined by social existence, reflecting social existence. It reflects directly the living

\footnotetext{
${ }^{1}$ Dictionary of Philosophy (1986), Progressive Publishing House, Moscow, pp. 523.

${ }^{2}$ Mark and Ph. Angghen (1993), Complete Works, Volume 13, National Politics Publishing House, Hanoi, p. 15
} 
conditions, circumstances and living environment of people, through the subjective lens of the individual; reflects the production level, the civilization level of the times, the cultural tradition, as well as many other human relationships. Therefore, social psychology reflects social existence in a direct, rich and vivid way. The reflection of social psychology on social existence is a specific reflection, on the one hand, it shows the dynamism of consciousness, on the other hand, it shows the conservatism of habits, customs, traditional practices. Therefore, social psychology does not always reflect positively and properly the development of social existence, it affects back to social existence, can promote or hinder the development of social existence. society in general. Of course, as a part of social consciousness, reflecting social existence and determined by social existence, changes in social existence inevitably lead to changes in social consciousness. society, including social psychology. However, social psychology has great sustainability and inertia. It may persist even if the socioeconomic basis for its existence has been removed. Thus, social psychology is not something that is available but it is a product of a combination of many factors in the process of human development, formed under the direct influence of productive working conditions, their activities. It reflects and is influenced by social existence in a vivid and rich way. Therefore, with different natural and social conditions, different groups of people will have different psychosocial characteristics.

\subsubsection{The concept of Vietnamese smallholders' psychological}

Smallholders' psychological in Vietnam is a type of social psychology, so it has all the characteristics of social psychology as described above. In addition, it also has its own characteristics determined by the smallholder economy, by the production and living conditions of the farmers themselves. The psychology of smallholders' psychological in Vietnam was born, formed from the reflection of the characteristics of the smallholder economy. "Smallholders' psychological economy is an agricultural economy in a state of small production in the way a farmer owns a little land and produces for himself.". It is the basis for the formation of smallholder mentality, because social psychology is a reflection of social existence, whose social existence at each historical period is basically the production base of that society. Living in the conditions of a small-scale farming economy, farmers form a psychological characteristic that is characteristic of their group, reflecting the living conditions of their group - called smallholder mentality.

However, the psychology of smallholders' psychological in Vietnam is not a simple sum of the psychology of each individual farmer, but a distillation of the most characteristic psychological features of this class, reflecting the living conditions, complete the landscape, the way of life of farmers over many generations. Therefore, Vietnamese smallholder psychology is a type of social psychology, including such phenomena as feelings, moods, beliefs, desires, needs, habits, customs, motives, attitudes, the interests, preferences, trends... of the peasantry were formed under the direct influence of the small-scale economy; The unique working and living conditions of farmers, agriculture and rural areas have produced, decided and influenced their attitudes, behaviours, and behaviours. The subject of that mentality is the farmer, but the rural lifestyle mentality not only exists and manifests in farmers but also manifests in people of other classes and classes in society. In fact, there are many people and social groups who have been living and living in rural areas but do not work in agriculture or are not directly influenced by the agricultural or rural economy, such as: in old society, it was the Confucianists, the monks...

In today's new society, those are cadres and teachers who work in rural areas but directly receive salaries from the state; cadres and workers whose offices, factories and enterprises are located in rural areas; people living in rural areas but taking trade, mechanical manufacturing services... as their main income, etc. On the other hand, through indirect influence, even people living in urban areas still bring smallholder mentality. The psychology of smallholders' psychological first shows the psychology of the Vietnamese people, the Vietnamese nation in general, and then it shows the peculiarities of the particular social group, the Vietnamese rural lifestyle. That particularity is created by many factors, of which are directly working conditions and living methods. It is a small-scale, self-sufficient, self-sufficient economy, with the nature of public land and public land on land; is the struggle with the harshness of nature, natural disasters, enemy sabotage in the labor of the farmers. In the process of that activity, they themselves have influenced each other to create social relationships, and also created their own psychological features. And this has also created the basis to distinguish their psychology from that of other population groups such as bourgeoisie, landlords, intellectuals... The psychology of smallholders' psychological in Vietnam is a very complicated phenomenon with many characteristics: the bad, the good, the positive, the negative are mixed and interwoven. Besides the psychological characteristics of smallholders' psychological with positive values such as: patriotism, community solidarity, love of labor, diligence, thrift, optimism in life; respecting people, respecting emotions, respecting morality, respecting honor..., there are still negative psychological characteristics such as: psychology of production is fragmented, conservative, in favor of experiential thinking; narrow-mindedness, selfishness, locality, freedom, arbitrariness, lack of discipline,

\footnotetext{
${ }^{1}$ Phan Huy Le, Vu Minh Giang (Editor), (1996), Traditional values and Vietnamese people today, Publishing House, Social Sciences, Hanoi, volume 2 , page 120 .
} 
discipline, more respect than the law... That is the duality of both unity and contradiction in the psychology of smallholders' psychological in Vietnam.

\subsection{Positive and negative effects of smallholder mentality on socio-economic development in Vietnam today 3.2.1. Positive influence of smallholder mentality on socio-economic development in Vietnam today}

The tradition of solidarity and community attachment is one of the outstanding psychological characteristics of Vietnamese people. Along with other institutions and institutions, this psychological trait is one of the important factors contributing to the organization, stability, and discipline of society, and contributes to creating conditions for each citizen to live peacefully. focus on labor and production, contributing to the development of the economy. Moreover, the spirit of solidarity, mutual love of the Vietnamese community has contributed to encouraging and comforting each individual when they encounter difficulties, failures, risks in business and in life. Therefore, they feel cared for by the community and society, avoiding the feeling of loneliness, being abandoned, being pushed out of the community and society. This is clearly shown throughout the history of nation building and defense of the Vietnamese nation. From the past until now, whenever the country has foreign invaders or when the country is at peace, the spirit of national solidarity of the Vietnamese people remains an eternal value, especially in the more difficult and difficult conditions. danger, the strength of that spirit rises and shines.

Only in the first twenty years of the 21 st century, Vietnam has been affected by the global economic and financial crisis and the great damage caused by successive natural disasters, but with the spirit of solidarity. With the spirit of solidarity, mutual love, love and help, the Vietnamese people have overcome difficulties and stabilized life and society. And especially in the past nearly two years, since the appearance of the Covid-19 epidemic in Wuhan (China) until now, Vietnam in particular and the whole world in general are facing the epidemic situation. The disease is complicated and unpredictable, leading to many countries unable to control the epidemic, with a high number of deaths such as India, Brazil, France...; The unemployment rate increased, the economy fell into crisis, the lives of people in these countries were extremely difficult...

In the face of the evolving, complicated and unpredictable situation of the Covid-19 epidemic, the entire Vietnamese nation has determined, joined forces and united with the Government and authorities at all levels to fight the epidemic with the motto "Fighting epidemics like Against the enemy"; implement the "dual goal" of fighting the epidemic, developing the economy and society, ensuring social security and people's life; always associate economic development with equity and social progress; setting the goal of protecting the people's life and health as a top priority and an urgent task. Along with drastic measures of the Government and authorities at all levels, the support, consensus and solidarity of all people, Vietnam has achieved many great results. That is shown:

Firstly, the whole people have agreed and determined to implement the slogan "Fight against epidemics like fighting invaders", well implementing the recommendation " $5 \mathrm{~K}$ of the Ministry of Health" (5K means 5 requirements that every citizen must fulfill to Covid-19 disease prevention and control: Masks - Disinfection Distance - Medical declaration - Do not gather in large numbers. When detecting an infected person in the community, quickly implement the following methods: containment, isolation, tracing and epidemic suppression. Therefore, the epidemic was controlled, controlled and gradually pushed back... In Vietnam, from the first case to date, the number of infected people is: 8791 people; The number of people who have been cured of the disease is: 3368 people, the number of people who have died: 53 people $^{1}$. The sick patients are treated and cared for with dedication and care. Compared to other countries in the region and the world, Vietnam has controlled and controlled the epidemic, so the rate of infected people and the rate of patient deaths is the lowest. In order to prevent and control the epidemic in a long-term, strategic way and decisively to get rid of the pandemic, in Vietnam, a "Vaccine Fund for Covid-19 Prevention and Control" has been established. The launching event of the "Vaccine fund for prevention and control of Covid-19" on June 5, 2021 in Hanoi has further demonstrated the kindness and strength of solidarity of the entire Vietnamese nation, businesses and overseas Vietnamese. Foreign workers and expatriates... have responded, supported and contributed to the Fund with the spirit of "One tree can't make a high mountain, Three trees together make a high mountain" in order to realize the goal of early vaccination for free for the entire population, soon repel the epidemic, bring safety and health to everyone. With its efforts in disease prevention and control, Vietnam has been highly appreciated by the world community for its results in the prevention and control of the Covid-19 epidemic.

Secondly, effectively implementing the goal of "both anti-epidemic and production", not to break the production chain, so production activities are always maintained and the economy develops. Generally for the first 5 months of 2021, "index of industrial production increased by $9.9 \%$ over the same period last year, of which the processing and manufacturing industry increased by $12.6 \% " 2$; "Commodity export turnover was

\footnotetext{
${ }^{1}$ Ministry of Health, Department of Information Technology, Update on the Covid -19 situation in Vietnam, at 6:48 am, June 7, 2021 , page 1.

${ }^{2}$ General Statistics Office, Report on socio-economic situation in May and first 5 months of 2021, May 28, 2021, page 4
} 
estimated at 130.94 billion USD, up $30.7 \%$ over the same period last year, of which the domestic economic sector reached 33.06 billion USD, up $16.6 \%$, accounting for $25.2 \%$ of total export turnover; the foreign-invested sector (including crude oil) reached USD 97.88 billion, up 36.3\%, accounting for $74.8 \% .{ }^{1}$. Gross domestic product (GDP) in the first quarter of 2021 was estimated to increase by $4.48 \%$ over the same period last year, higher than the growth rate of $3.68 \%$ in the first quarter of $2020^{2}$.

Third, the results of the Government's social security policies and solutions to support near-poor households continue to be effective. As of May 2021, this is the 11th consecutive month of no shortage of food nationwide. The lives of people in epidemic-affected areas are guaranteed.

Fourth, the political situation is stable, national security and defense are maintained...The spirit of solidarity and attachment of the Vietnamese people has been and will contribute to creating a positive socio-psychological environment for each citizen to actively promote their individual capacities. This tradition, not only plays an important role in social relations, but also holds a special place in emotional life. Its positive value has created a synergy to help people overcome all circumstances, is a solid support for each individual. Therefore, when they are far away from their homeland, out of affection for the community, they often organize a local council, on that basis to establish and organize activities of mutual assistance and help, and promote traditions. good unity of the nation. Since ancient times, community values have always been placed in a priority position compared to individual values, which have contributed to keeping the village stable, creating conditions for each person to perform well their associated functions in the community. extreme conditions (natural disasters, enemy sabotage, epidemics...). Community values hidden in social institutions and institutions, from material to spiritual, from visible to invisible, crystallize into lifestyles, standards, customs and practices... protected, preserved and developed by generations of Vietnamese people. All words and deeds that belittle or infringe on community values are often severely punished and condemned. Living in a psychological environment where community values are always upheld and valued has set a requirement for each individual to constantly improve and train their consciousness and qualities to meet the requirements of the community. community and society. This tradition contributes to the formation of a life of gratitude, kindness and responsibility to the collective. These values, which are well preserved and promoted, will be a positive factor contributing to limiting the introduction and expansion of the pragmatic, selfish, utilitarian, individualist lifestyles that oppose the ideas harmful, social evils are taking advantage of the market economy to penetrate into Vietnamese social life today. Respectful psychology, a lifestyle of gratitude, respect for obligations, and respect for community rules of the Vietnamese people are one of the basic reasons for a stable society, rarely having major social conflicts. Vietnam is a country of many ethnic groups, some of them have migrated from distant lands to live and have voluntarily become a member of the great family of Vietnamese peoples. This explains why there are no ethnic conflicts in Vietnam, which are complex and difficult issues that are not easily resolved in some countries around the world. This is a great advantage in psychology and national character, creating a good condition and environment for Vietnam to not only develop its economy, preserve the cultural identity of each nation, and maintain social stability. but also less need to deal with issues of ethnic conflicts like some countries in the world.

\subsubsection{Negative effects of smallholders' psychological mentality on socio-economic development in Vietnam} today

Smallholders' psychological mentality is very conservative and has great inertia, inhibiting socio-economic development in Vietnam as shown below:

First of all, in the tradition, Vietnamese people have little affirmation of their personal ego and independent personality. They rarely address in community relationships, but often define their position and responsibilities in those relationships to have the corresponding title: brother, sister, son. grandchild, etc. This way of addressing shows the dominant position of "the community" over "the individual". The individual is almost dissolved into the community, the individual person is almost hidden by the community person. This cultural feature is present in each Vietnamese people, clinging to them firmly and persistently, becoming a psychological feature of sustainable Vietnamese people. If in wartime it is reasonable, justifiable and necessary to uphold community values and put community interests above personal interests, then in the conditions of global integration, each individual needs to be protected. affirm the ego, dare to think, dare to do, dare to take responsibility. That met a huge obstacle of the dominant community mentality. This mentality is one of the sources of the habit of relying on the collective, not daring to take responsibility: "No one in the common father cries / no one closes the temple door"; psychologically for peace, passively like "the country can't stand it", lack of will to advance, "what's wrong with me" or "I'm second if you're the first/ If you're better than me, I'm third", just worried coping, passive, lack of social responsibility, lack of sense of citizenship. Therefore, the idea of respect has the opportunity to develop, people always think "close the door and tell each other", "Pull out the small rope, afraid to shake and touch the big forest". Therefore, not encouraging the development of positivity, dynamism and creativity of

\footnotetext{
${ }^{1}$ General Statistics Office, Report on socio-economic situation in May and first 5 months of 2021, May 28, 2021 , page 12.

${ }^{2}$ General Statistics Office, Socio-economic situation report, first quarter, 2021, March 28, 2021, page 2.
} 
individuals. Those are obstacles to socio-economic development, when the reality of the country requires each citizen to be independent, decisive, dare to think, dare to do, dare to take responsibility, being active, dynamic and creative in the context of integration with countries in the region and the world. It is necessary to distinguish the negative side of community psychology from the tradition of attaching importance to community values which is one of the traditional values of the Vietnamese nation that has been tested over time. As a result, Vietnamese people constantly practice their personal qualities towards the beautiful community values. The respect for community is a valuable traditional value, the source of the country's endogenous strength. This is different from its flip side, which is the mentality of relying on, relying on, looking forward to the collective...

Secondly, the negative side of the community solidarity mentality has caused many difficulties and obstacles to the socio-economic development process in Vietnam today such as: egalitarianism, locality , jealousy, envy, disunity, not wanting others to be superior to themselves, other villages to be different from their own village, the mentality of "the king's magic loses to the village rules", the conservative mentality, stagnation, unwillingness to innovate... This negative sentiment sharply contradicts the requirements to respect economic contracts, economic terms in the development of a socialist-oriented market economy, integration and exchanges with other countries. countries in our region and around the world. The relatively complete autonomy and selfgovernance of the village-commune and the local mind of the ancient farmers often made them see only the narrow interests of their own village and not the interests of other villages and of the whole community. country (except when the country is invaded and threatened by natural disasters and epidemics). Stemming from the local mentality, many villages (especially craft villages) have strict regulations in order to hide their profession by not passing it on to other villagers, even to their children, for fear that they would bring the know-how to another village, to another place. That narrow-mindedness, selfishness, and professional "secret" still exist among rural residents, especially in traditional craft villages, affecting integration and economic development in Vietnam. The current.

Third, in the traditional Vietnamese village-commune, it is basically an agricultural village-commune. The village-commune economy is self-sufficient and self-sufficient. All activities of the village-commune are closed, with little interaction with the outside. Therefore, the mentality of small-scale production has been formed in farmers, scattered, self-sufficient and self-sufficient. This production method along with the closedness in family and village relations has led to the thinking style of Vietnamese farmers without foresight, no strategy, and conservative in the reception of new things. new. That way of thinking, that way of thinking, that way of looking, along with the timidity and lack of self-control of the individual in the community are conditions for the emergence of a good-natured mentality; Even if hungry or full, they cling to their village and stay in their village. Farmers like stability, peace of mind, are afraid to go far to do business, broaden their horizons, but just want to "settle and live happily". From there, a sense of peace arose. Most Vietnamese people, especially farmers, lead a peaceful and quiet life, afraid of change. If Westerners living in an industrial society can change their place of residence a few times a year, on the contrary, small farmers living in a civilized agricultural society may live in only one place for their entire life. place. This is also an obstacle in site clearance when carrying out the construction of a traffic project or an industrial park, in the redistribution of labor or in international cooperation on labor, etc.

Fourth, when Confucianism was introduced into Vietnam, the land of traditional Vietnamese villages and communes was considered as fertile ground for the seeds of Confucian ideology to have conditions to form and develop. Confucianism has made certain contributions to the development of Vietnam's feudal society. The influence of Confucianism and the village-commune caste system, combined with the mentality of honor, has led to overemphasis on study and academic achievement. This is one of the factors creating the tradition of studiousness of Vietnamese people. The respect for reputation and honor - the result of the community lifestyle and the appreciation of the community's recognition, is, at a reasonable level, something to be cherished, cherished, and inherited. However, it is worth mentioning here that, in reality, Vietnamese people used to attach too much importance to academic degrees in a formal way "a piece in the middle of the village is equal to a sieve in the kitchen corner". Moreover, the negative side of the mentality of being overrated in reputation is also expressed in formal pomp and "disgraceful" ${ }^{1}$. If in daily life, Vietnamese people are very simple and thrifty, then during festivals, cults, Tet anniversary, funerals, etc., Vietnamese people do not spare money and waste money. If in Vietnamese villages in the primitive and rural communes, the organization of community meals was an activity with a noble purpose, tightening community sentiment, then in feudal times, in many where, that tradition is distorted into customs. Currently, the organization of community dining has lost its impartiality and transparency, showing the spirit of mutual support, solidarity and help among people. In today's Vietnamese society, although in many places the people and authorities have perceived and criticized the organization of weddings and funerals, festivals... too lavish and wasteful and encourage their simple, economical organization. However, due to the influence of this psychological trait, in the current social life of Vietnam, the above

\footnotetext{
${ }^{1}$ like to express in terms of external appearance, but in fact the inside does not correspond to the external form expressed.
} 
phenomena not only occur during Tet holidays, filial piety and joy occasions, but also penetrate into other occasions. meetings, summaries, birthday celebrations, passing, receiving degrees, even when buying expensive personal items. That phenomenon has partly left behind heavy damage both in terms of economy and culture society in Vietnam today.

On the other hand, it is also due to the influence of Confucianism that in Vietnamese society, there was a mentality of disdain for business activities, only attaching importance to: Literature, Dao and Ethics. Therefore, the psychology of disdain for the trade has been deeply rooted in people's thoughts, making the trade (commercial profession) in the history of Vietnam impossible to develop. This has made Vietnam's agriculture before the August revolution fall into an isolated and closed state. Today, the thought of respecting farmers and remembrance of love still exists in many people, and it is difficult to overcome immediately. This is a difficulty to achieve the goal of economic restructuring towards modernity, in which industry, commerce and services account for a large proportion in the entire national economy; is an obstacle in the process of building a market economy and the process of international economic integration in Vietnam today.

\subsection{Some basic solutions to promote the positive influence and overcome the negative influence of smallholders' psychological mentality on socio-economic development in Vietnam today 3.3.1. Developing a socialist-oriented market economy}

Developing a socialist-oriented market economy in Vietnam will create conditions and an objective basis to promote positive influence and overcome the negative influence of smallholders' psychological mentality on development. socio-economic, because:

Firstly, the market economy forces farmers to be dynamic, creative and responsive in the process of production, distribution and consumption of products. This is far different from the previous habit of passive, expecting and relying in the economy, which will create socio-economic premise for overcoming the mentality of localism, localism, and conservationism. self-contained, self-contained by the people, breaking the traditional mentality of small production, self-sufficiency and self-sufficiency of farmers. The change and flexibility of production under the market mechanism makes the conservatives, stagnant, always clinging to the existing as the immutable values must also change. These changes will contribute to the formation of favorable social conditions and environments for the development of scientific thinking, overcoming the experiential and shortsighted thinking of the Vietnamese people today.

Second, the market economy requires each citizen to be able to make their own decisions and take responsibility for their thoughts and actions, forcing them to learn about the requirements, regulations and standards in the regulations. production process; learn about the law, improve legal knowledge and act according to the law, thereby forming legal consciousness, legal personality and law-abiding behavior. This is a favorable condition for socio-economic development in Vietnam

Third, in the market economy, economic activities must comply with the requirements of objective economic laws. This requires producers and traders to grasp and comply with those rules. Therefore, it will help break down the subjectivity, arbitrariness, and experience in Vietnamese farmers. In such conditions, the contingent of state officials and civil servants, especially the contingent of managers and leaders - those who practice official duties and hold important positions in the state apparatus, are even less able to do their jobs. According to old experience, it is not possible to maintain a subjective and arbitrary mentality, but to gradually improve the level of culture, especially the level of legal culture, professional expertise, eliminate negative habits, Only backward in the mentality of rural lifestyle can meet the requirements of the reality of socio-economic development in Vietnam.

Thus, when developing a socialist-oriented market economy in Vietnam, the positive manifestations of the smallholders' psychological mentality are still aroused and promoted in accordance with new requirements and tasks, at the same time. The negative aspects of smallholders' psychological mentality are also gradually overcome. Besides, there are also new psychological features such as dynamism, creativity, dare to think, dare to do... These are psychological features that have a positive influence on the development of the market economy in the context now in Vietnam.

However, the market economy not only creates favorable conditions and environment for the promotion of the positive of the smallholders' psychological mentality, but it is also an environment that increases the negative side of this mentality, because in Vietnam the The newly formed socialist-oriented market economy has not been synchronized, so its negative side has left heavy consequences. Fair and fair competition is a driving force for all production and business entities to constantly improve their qualifications in all aspects, but besides that, there is also the phenomenon of unfair competition, competition that overwhelms each other. between production and business entities, so it can lead to production disorder, wasted potential, bankruptcy, unemployment, surplus crisis... That will lead to the rich-poor divide, the inequality and discrimination in the population. Therefore, standards and value ladders will be replaced and reversed. It can lead to degradation of moral values, erosion of good traditions as well as cultural values of the Vietnamese people which have been preserved from time 


\section{immemorial.}

\subsubsection{Promote the cause of industrialization, modernization and development of the production force}

Promoting the cause of industrialization, modernization and development of the productive forces is the basic solution to promote the positive influence and overcome the negative influence of the smallholders' psychological mentality on socio-economic development. in Vietnam today, because:

Firstly, industrialization and modernization have both created modern material and technical bases and created a favorable social environment and environment. Those are the most important and decisive factors to overcome the negative influence of smallholders' psychological mentality. Industrialization and modernization, on the one hand, both have a direct impact and gradually eliminate the negative manifestations of smallholders' psychological mentality, on the other hand, give rise to new psychological features such as: high discipline, agile behavior, creative thinking, dynamism, sensitivity... Therefore, it creates favorable conditions and has a positive influence on the country's socio-economic development. If, in the small-scale economy, small production is selfsufficient and self-sufficient, farmers are only used to following experience, using rudimentary manual tools and low technical level, then when carrying out industrial In the process of modernization and modernization, that habit will be gradually eliminated by the introduction of scientific and technological advances into production, and manual tools will be replaced by modern, efficient, and economically efficient machines. All these changes require that every citizen must actively study, improve their knowledge and expertise, and equip themselves with scientific and technical knowledge to be able to work in the field. New and modern production environment as well as new capacity to solve complex problems arising in production and life. Therefore, farmers will have a change in vision and thinking; the way of thinking based on experience, short-sighted, conservative, afraid to change, afraid to absorb new things is gradually eliminated; Observation, critical thinking, methods of assessment, recognition and problem solving will be developed on the basis of science. Scientifically grounded thinking methods will be gradually established to replace the intuitive, emotional, and unsubstantiated way of thinking of farmers.

Second, industrialization and modernization will inevitably lead to a shift in economic structure from an economy with a basic structure of agriculture to a modern industrial-agricultural-service economic structure. that growth rate and industrial share will increase; shift the labor structure in rural areas in the direction of reducing the proportion of agricultural laborers shifting to services, handicrafts, and processing industries to improve the quality and value of agricultural products... is changed with industry, tourism - services playing the leading role, the socio-economic life in agricultural and rural areas has profound changes, creating favorable conditions for the development of the economy. promote the positive influence, overcome the negative influence of the psychology of smallholders' psychological in Vietnam, contributing to socio-economic development.

The first change is in the process of division and rearrangement of labor. Masses of farmers will become workers in industries and services. From where farmers are only used to simple labor with rudimentary tools and outdated technical skills, they now have to get used to a new working environment with machines, tools, and technical processes. new. Those tools and processes require people to form new labor skills, to have precise manipulations, to strictly comply with regulations on time, labor discipline... The implementation These requirements also mean that employees must improve their working style and attitude. The free, undisciplined lifestyle, coming late and leaving early, the slow, slow and irresponsible lifestyle of the farmers will gradually be replaced by a strict disciplined lifestyle and working style. the urgency and agility of industrial production.

Third, the process of industrialization and modernization of agriculture and rural areas inevitably leads to rapid rural urbanization. As a result, Vietnam's rural economy - society becomes more vibrant, farmers also become more active. Living and working conditions with industrial style will change a series of old and outdated customs and working habits and activities such as: a closed lifestyle, heavy-hearted behavior, and marginal style. slow, slow... of Vietnamese farmers.

Fourth, the process of industrialization and modernization in general and in rural areas in particular have both direct and indirect impacts on overcoming the negative side and promoting the positive side of the smallholders' psychological mentality. among the people and the contingent of cadres and civil servants, including leaders and managers at all levels. Therefore, in order to successfully implement the cause of industrialization and modernization in Vietnam, the role of subjective factors, of all classes of people, of cadres and civil servants, especially the contingent of cadres and civil servants. Leadership is extremely important. They are not only subject to the influence of the process of industrialization and modernization in order to gradually shed the remnants and outdated smallholders' psychological mentality, but moreover, in fact, they must be one of the key factors driving this process. They are the forces directly involved in the process of industrialization and modernization, and in the process of doing so, their capacity and qualifications will be enhanced, thereby gradually eliminating negative influences. extreme in their petty peasant mentality. In the process of industrialization and modernization in Vietnam, the contingent of cadres and civil servants in charge of leadership and management at all levels is responsible for acquiring, applying, implementing and concretizing the road map. guidelines, guidelines and policies on industrialization and modernization into the field of practice 
they are in charge of. However, guidelines and policies are products of high-level thinking, so understanding and perceiving them requires cognitive subjects to have thinking at a certain level of development. If only by way of experiential, fragmented and scattered thinking, leading cadres cannot understand and master their contents. That leads them to also not be able to implement and concretize guidelines, guidelines, policies... into their localities and units properly and effectively. Therefore, in order to complete the task, the contingent of cadres and civil servants in charge of leadership and management must study, train to improve their qualifications and meet the requirements of the job. Through this process, their thinking level is developed, the limitations of smallholders' psychological mentality will also be gradually overcome.

Thus, the process of industrialization and modernization in general and industrialization and modernization of agriculture and rural areas in particular in Vietnam today will create a fundamental change in the face of socio-economic life. society, creating a material premise, a favorable social environment for the improvement of the people's cultural and spiritual life, creating a rural psychological atmosphere, healthy farmers, and forming a civilized new countryside, modern. This is a decisive factor to limit the negative effects of smallholders' psychological mentality on socio-economic development in Vietnam.

\section{Conclude}

Smallholders' psychological in Vietnam is a type of social psychology that arose from the reflection of the characteristics of the smallholders' psychological economy. Besides the psychological characteristics of smallholders' psychological with positive values such as: patriotism, community solidarity, love of labor, diligence, thrift, optimism in life; respecting people, respecting emotions, respecting morality, respecting honor, etc, there are still negative psychological characteristics such as: psychology of production is fragmented, conservative, in favor of experiential thinking; narrow-mindedness, selfishness, locality, freedom, arbitrariness, lack of discipline, discipline, more respect than the law... That is the duality of both unity and contradiction in the psychology of smallholders' psychological in Vietnam. The psychology of smallholders' psychological in Vietnam affects in two directions: positive (positive) and negative (negative) on socio-economic development in Vietnam.

Promoting the positive effects and overcoming the negative influence of smallholders' psychological mentality on economic development in Vietnam is now a necessary, difficult and long-term task. To carry out that task, it is necessary to implement a number of basic solutions as follows: Developing a socialist-oriented market economy and accelerating industrialization, modernization and development of production forces. These solutions will create conditions, premise, objective basis, social basis and favorable social environment; are the most important and decisive factors to overcome the negative influence of smallholders' psychological mentality. Besides these solutions, it is necessary to pay attention to other solutions such as: improving cultural life, improving outdated customs and practices, raising people's legal awareness, and implementing democracy in rural areas etc. The synchronous combination of solutions will bring high efficiency in promoting positive influences and overcoming, limiting the negative effects of smallholders' psychological mentality on socioeconomic development. association in Vietnam today.

\section{References}

1. Phan Ke Binh (1990), Vietnamese customs, Ho Chi Minh City Publishing House.

2. Phan Dai Doan (1992), Vietnam Village - Some Socio-Economic Issues, Social Science Publishing House, Hanoi.

3. P. Gourou (2003), The farmer in the Tonkin Delta, Young Publishing House, Hanoi.

4. Tran Van Giau (1980), Traditional spiritual values of the Vietnamese nation, Social Science Publishing House, Hanoi.

5. Pham Minh Hac (editor) (2004), Vietnamese psychology going into industrialization and modernization Things to overcome, National Political Publishing House, Hanoi.

6. Phan Huy Le, Vu Minh Giang (editor) (1994), Traditional values and the current Vietnamese people, Volume 1, Social Sciences Publishing House, Hanoi.

7. Phan Huy Le, Vu Minh Giang (editor) (1996), Traditional values and the current Vietnamese people, Volume 2, Social Science Publishing House, Hanoi.

8. Do Long (2000), Community and individual relations in farmer psychology, Social Science Publishing House, Hanoi.

9. Phan Ngoc (1994), Vietnamese Culture - A New Approach, Culture and Information Publishing House, Hanoi. 10. C. Mark and Ph. Angghen (1993), Complete Works, Volume 13, National Political Publishing house, Hanoi.

11. Cao Thi Sinh (2015), Influence of rural lifestyle mentality on building a socialist rule of law state in Vietnam, Political Theory Publishing House, Hanoi.

12. General Statistics Office, Socio-economic situation report, first quarter, 2021, March 28, 2021.

13. Cao Thi Sinh (2021), Rural Lifestyle in Vietnam - Values and Drawbacks, Journal of Philosophy, Culture and 
Religion, ISSN 2422-8443 An International Peer-reviewed Journal, Vol.53, page 8-14.

14. General Statistics Office, Report on socio-economic situation in May and first 5 months of 2021, May 28, 2021.

15. Philosophical Dictionary (1986), Progressive Publishing House, Moscow.

16. Le Huu Xanh (editor) (2005), Negative influence of rural lifestyle mentality on leaders and managers of state-owned enterprises, Political Theory Publishing House, Hanoi. 